\title{
REAÇÃO DE CULTIVARES DE COENTRO EM DIFERENTES CONCENTRAÇÕES DE INÓCULO DE MELOIDOGYNE INCOGNITA RAÇA 1
}

\author{
Ana Maria Maciel dos Santos ${ }^{1}$, Kleyton Danilo da Silva Costa ${ }^{2}$, Denisson Lima do \\ Nascimento $^{3 *}$, Dimas Menezes ${ }^{4}$, Jordana Antônia dos Santos Silva ${ }^{5}$, Michelangelo de Oliveira \\ Silva $^{6}$, José Luiz Sandes de Carvalho Filho ${ }^{7}$
}

\footnotetext{
${ }^{1}$ Doutora em Melhoramento Genético de Plantas, Pesquisadora no Centro de Tecnologias Estratégicas do Nordeste, Recife, PE.

${ }^{2}$ Docente, Melhoramento Genético de Plantas, Instituto Federal de Educação, Ciência e Tecnologia de Alagoas (IFAL), Piranhas, AL.

${ }^{3}$ Graduando, Engenharia Agronômica, Instituto Federal de Educação, Ciência e Tecnologia de Alagoas (IFAL), Piranhas, AL.*E-mail do autor correspondente: denisso2011_@ hotmail.com

${ }^{4}$ Docente, Botânica, Universidade Federal Rural de Pernambuco (UFRPE), Recife, PE.

${ }^{5}$ Mestranda, Melhoramento Genético de Plantas, Universidade Federal Rural de Pernambuco (UFRPE), Recife, PE.

${ }^{6}$ Docente, Ciência do Solo, Instituto Federal de Educação, Ciência e Tecnologia de Alagoas (IFAL), Piranhas, AL.

${ }^{7}$ Docente, Fitotecnia, Universidade Federal Rural de Pernambuco (UFRPE), Recife, PE.
}

Recebido: 19/03/2020; Aceito: 06/04/2021

RESUMO: A busca por genótipos resistentes aos nematoides tem sido foco de diversos programas de melhoramento genético no país, para diferentes espécies cultivadas. $\mathrm{O}$ Coriandrum sativum L. está entre as hortaliças folhosas mais produzidas e consumidas no Brasil, especialmente nas regiões Norte e Nordeste. Contudo, a presença de nematoides tem sido fator limitante a sua produção, causando prejuízos aos produtores. Sendo fundamental a utilização de metodologia adequada na avaliação das cultivares e acessos disponíveis aos programas de melhoramento. Com isso, o presente trabalho avaliou cinco cultivares de coentro (Verdão, Tabocas, Tapacurá, Palmeira e HTV Dom Luiz) inoculadas na semeadura com diferentes concentrações de inóculo de Meloidogyne incognita raça 1 (0, 1.000, 2.000, $4.000,8.000$ e 16.000 ovos/planta), em um experimento conduzido no delineamento inteiramente casualizado com três repetições e parcela experimental constituída por quatro plantas. Após a semeadura iniciou-se a avaliação da germinação e manutenção do estande. Aos 30 dias após a inoculação verificou-se o comprimento do sistema radicular, a incidência de galhas, o número de galhas no sistema radicular, o número de ovos e fator de reprodução. Com base nas variáveis analisadas, a concentração de inóculo com 1.000 ovos/planta é a mais indicada, por possibilitar um bom desenvolvimento do sistema radicular e classificar corretamente os genótipos por meio do fator de reprodução do patógeno. Observou-se também que a inoculação na semeadura e avaliação aos 30 dias foram suficientes para diferenciar as cultivares avaliadas e verificar a infecção causada pelo nematoide.

Palavras-chave: Coriandrum sativum L. Nematoides das galhas. Melhoramento vegetal. 


\title{
REACTION OF CORIANDER CULTIVARS AT DIFFERENT INOCULUM CONCENTRATIONS OF MELOIDOGYNE INCOGNITA RACE 1
}

\begin{abstract}
The search for nematode-resistant genotypes has been the focus of several genetic improvement programs in the country for different cultivated species. Coriandrum sativum L. is among the most produced and consumed potherbs in Brazil, especially in the Northern and Northeastern regions. However, the presence of nematodes has been a limiting factor in their production, causing losses to producers. The use of adequate methodology in the evaluation of the cultivars and easy accesses to breeding programs is fundamental. The present study evaluated five cultivars of coriander (Verdão, Tabocas, Tapacurá, Palmeira and HTV Dom Luiz) inoculated in sowing with different inoculum concentrations of Meloidogyne incognita race $1(0,1,000,2,000,4,000,8,000$ and 16,000 eggs/plant), in an experiment conducted in and completely randomized design with three replicates and experimental plot consisting of four plants. After sowing, the germination and maintenance of the stand began to be evaluated. At 30 days after inoculation, the root system length, the incidence of galls, the number of galls in the root system, the number of eggs and the reproduction factor were verified. Based on the analyzed variables, the concentration of inoculum with 1,000 eggs/plant is the most indicated, since it allows a good development of the root system and correctly classify the genotypes through the reproduction factor of the pathogen. It was also observed that inoculation at seeding and evaluation at 30 days were sufficient to differentiate the evaluated cultivars and to verify the infection caused by the nematoid.
\end{abstract}

Key words: Coriandrum sativum L. Gill nematodes. Plant breeding.

\section{INTRODUÇÃO}

Nos sistemas produtivos de hortaliças folhosas são diversos os fatores limitantes à produção, que vão desde os estresses abióticos aos estresses causados por pragas e doenças, como as causadas por nematoides.

Dentre os vários gêneros de nematoides presentes em áreas produtoras de hortaliças folhosas causando prejuízos aos produtores, destacam-se os nematoides Xiphinema spp., Longidorus africanus, Pratylenchu spenetrans, Rotylenchus robustus e os nematoides das galhas (Meloidogyne spp). No Brasil, os nematoides das galhas são causadores dos maiores problemas nas hortaliças folhosas, com ênfase para as espécies $M$. incognita e M. javanica, com ampla distribuição nas regiões produtoras (PINHEIRO et al., 2010a).

O coentro (Coriandrum sativum L.) é uma das folhosas atacadas pelos nematoides das galhas sendo o $M$. incógnita raça 1 o de maior importância. Esse patógeno apresenta atividade durante todo o ano em locais de climas quentes e solos úmidos, sendo os juvenis de segundo estádio (J2) as formas de vida que infectam as raízes da cultura formando galhas isoladas, de pequenas dimensões, distribuídas ao longo da raiz (PINHEIRO; PEREIRA, 2016).

Apesar dos nematoides das galhas serem responsáveis por perdas de aproximadamente $5 \%$ na agricultura mundial, as tecnologias para controlá-los avançaram pouco nos últimos 30 anos (MCCARTER, 2008). Na tentativa de controlar tais patógenos, diversos métodos são 
utilizados: culturais, físicos, biológicos (SANTOS et al., 2006), químico (FERREIRA et. al., 2013) e o uso de cultivares resistentes, nem sempre disponíveis no mercado (MCCARTER, 2008), como é o caso do coentro.

As metodologias para verificar o comportamento das espécies vegetais quanto à reação aos nematoides das galhas baseiam-se na inoculação dos ovos do patógeno aos 13 - 15 dias após a semeadura (Meloidogyne incognita, Meloidogyne mayaguensis, Meloidogyne javanica, e M. Paranaensis), com avaliação da incidência de galhas, número de galhas, número de ovos e fator de reprodução aos 45-60 dias após a inoculação (PINHEIRO et al., 2010b; DIASARIEIRA et al., 2009). Embora tal metodologia seja utilizada para diferentes espécies vegetais (alface, tomate, pimentão, coentro, cenoura, girassol, entre outras), é importante levar em consideração o ciclo da cultura e técnica de cultivo, a fim de estabelecer a metodologia que se adeque a cada situação específica.

Neste sentido, a busca por identificar a concentração de inóculo mais indicada para realizar a avaliação da reação de resistência em espécies cultivadas tem motivado trabalhos em diferentes culturas, como maracujazeiro (EL-MOOR et al., 2009), cafeeiro (SANTOS, 2017), soja (TEIXEIRA, 2013), entre outras.

Para otimizar o processo seletivo e identificação de genótipos de coentro resistentes ao nematoide das galhas é fundamental o estudo de metodologia que possibilite a avaliação dos genótipos sem subestimar ou superestimar seus reais potenciais genéticos. Nesta finalidade, a inoculação do patógeno na semeadura pode ser uma opção que possibilite a seleção de indivíduos capazes de germinar e se desenvolver na presença do nematoide, limitando ou impedindo a infecção causada pelo mesmo, consequentemente mantendo o estande da cultura. Pois, o coentro é uma cultura implantada em canteiros por meio de semeio direto em sulcos onde as plantas permanecem até a fase de colheitas das folhas ou frutos (MAKISHIMA et al., 2010), estando desta forma, em contato com o nematoide desde a germinação.

Diante do exposto, o objetivo do presente trabalho foi verificar a reação de cinco cultivares de coentro inoculadas na semeadura com diferentes concentrações de inóculo de Meloidogyne incognita raça 1.

\section{MATERIAL E MÉTODOS}

O experimento foi conduzido na casa de vegetação da área de Fitotecnia do departamento de Agronomia da Universidade Federal Rural de Pernambuco (UFRPE) com localização a 8 $54^{\prime} 47^{\prime}$ 'S, $34^{\circ} 54^{\prime} 47^{\prime}$ 'W, altitude de 6 m, no período de abril a maio de 2016. As médias mensais de temperaturas registradas pela estação meteorológica do Recife Curado (automática) variaram em média entre 22,5 a $30,6^{\circ} \mathrm{C}$, para temperatura mínima e máxima, respectivamente (INSTITUTO NACIONAL DE METEOROLOGIA - INMET, 2018).

Utilizou-se o delineamento inteiramente casualizado com três repetições em arranjo fatorial composto pela interação entre cinco cultivares de coentro (Verdão, Tabocas, Tapacurá, Palmeira e HTV Dom Luiz) e seis concentrações de inóculo de $M$. incognita raça 1 $(0,1.000,2.000,4.000,8.000$ e 16.000 ovos/planta), sendo a parcela experimental composta por quatro plantas, totalizando 360 indivíduos. 
Os ovos foram obtidos de fontes de inóculo mantidas em tomateiros (Solanum lycopersicum cv. Santa Cruz) parasitados pelo nematoide. As raízes foram imersas em água para remoção do substrato e posteriormente, procedeu-se à extração dos ovos pela metodologia proposta por Hussey e Barker (1973) e modificada por Boneti e Ferraz (1981). A contagem do número de ovos foi realizada em lâmina de Peters em microscópio óptico com aumento de 40x. Após a contagem, a solução foi ajustada para as concentrações utilizadas no experimento.

Foram utilizados tubetes de $116 \mathrm{~mL}$ preenchido com o substrato comercial, onde foi realizada a semeadura de 2 sementes por tubete, a aproximadamente $1 \mathrm{~cm}$ de profundidade, seguindo-se da irrigação com água e posterior inoculação do patógeno com auxílio de uma seringa veterinária, diretamente no substrato.

A irrigação manual e diária foi realizada em quantidade suficiente para atender a demanda hídrica da cultura, tomando as devidas precauções para evitar a drenagem, evitando a lixiviação do inóculo. Após a germinação, verificou-se a porcentagem de plântulas emergentes (PPE), e por três dias da semana, realizou-se fertirrigação com solução nutritiva (200 g $1.000 \mathrm{~L}^{-1}$ de MAP, $400 \mathrm{~g} 1.000 \mathrm{~L}^{-1}$ de sulfato de magnésio, $25 \mathrm{~g} 1.000 \mathrm{~L}^{-1}$ de Quelatec, $25 \mathrm{~g} 1.000 \mathrm{~L}^{-1}$ de Ultraferro, $750 \mathrm{~g} 1.000 \mathrm{~L}^{-1}$ de nitrato de cálcio e $450 \mathrm{~g} 1.000 \mathrm{~L}^{-1}$ de nitrato de potássio.). Quando as plântulas apresentavam a primeira folha definitiva, procedeu-se o desbaste, deixando uma plântula por tubete.

Aos 30 dias após a inoculação do patógeno, foram realizadas as avaliações das variáveis: porcentagem de plantas sobreviventes (PPS), comprimento do sistema radicular em cm (CSR), incidência de galhas (IG), número de galhas no sistema radicular (NGSR), número de ovos (NO) e a estimação do fator de reprodução (FR). Utilizaram-se escalas de notas para as características incidência de galhas, número de galhas e número de ovos, sendo todas constituídas por cinco notas. Para incidência de galhas, nota $1=$ zero galhas; $2=$ uma ou duas galhas; 3 = três a dez galhas; $4=$ onze a 30 galhas e $5=$ mais de 30 galhas. Para o número de galhas, nota $1=$ número de galhas $\leq 10 ; 2=$ número de galhas $\geq 11$ e $\leq 20 ; 3=$ número de galhas $\geq 21$ e $\leq 30 ; 4=$ número de galhas $\geq 31$ e $\leq 40$ e $5=$ número de galhas $\geq 41$. Para o número de ovos, nota $1=$ número de ovos $<1200 ; 2=$ número de ovos de $1200-2400 ; 3=$ número de ovos de $2401-3600 ; 4$ = número de ovos de 3600 - 4800 e 5 = número de ovos $\geq$ 4801 (DINIZ, 2012).

Os ovos foram extraídos do sistema radicular, segundo a metodologia proposta por Hussey e Barker (1973) e modificada por Boneti e Ferraz (1981), posteriormente armazenados com água em recipientes identificados e colocados na câmara fria até a realização da contagem do número de ovos por planta. A quantificação do número de ovos foi realizada colocando-se $2 \mathrm{~mL}$ da suspensão de ovos em lâmina de Peters, sendo em seguida utilizado o microscópio com o aumento de 40X para visualização e contagem, utilizando contador mecânico com quatro dígitos.

Quanto à reação das cultivares de coentro ao patógeno foi utilizada a escala de Oostenbrink (1966), sendo consideradas resistentes as cultivares com FR $<1$ e suscetível as que apresentarem FR>1. O fator de reprodução (FR) é uma relação entre a população final e a população inicial do nematoide $(\mathrm{FR}=\mathrm{Pf} / \mathrm{Pi})$. 
O valor obtido para cada variável na parcela foi resultante da média aritmética das plantas presentes em cada parcela experimental. Os dados obtidos foram transformados por $\sqrt{x}$ adequando-se as suposições da análise de variância, exceto para as variáveis: emergência das plântulas, porcentagem de plantas e comprimento do sistema radicular. Posteriormente, submetidos à análise de variância, sendo as médias dos tratamentos comparadas pelo teste de agrupamento de Scott-Knott a 5\% de probabilidade. Efetuou-se a análise de regressão visando compreender o efeito das diferentes concentrações de inóculo sobre o número de galhas no sistema radicular e fator de reprodução em cada um dos genótipos de coentro avaliados. As análises foram feitas usando o aplicativo estatístico SISVAR (FERREIRA, 2011), sendo os gráficos das regressões significativas a $1 \%$ ou $5 \%$, elaborados no Excel.

\section{RESULTADOS E DISCUSSÃO}

A interação cultivares*inóculos foi significativa a 5\% de probabilidade para as variáveis NGSR e FR. Para IG e NO a interação entre as fontes de variação não foi significativa. Entretanto, ocorreram diferenças significativas nas fontes de variação cultivares e inóculos ao nível de $1 \%$ de probabilidade. Os coeficientes de variação oscilaram entre 16,92\% (IG) a 43,24\% (FR) (Tabela 1).

Tabela 1. Resumo da análise de variância dos caracteres incidência de galhas (IG), número de galhas no sistema radicular (NGSR), número de ovos (NO) e fator de reprodução (FR) em cultivares de coentro, inoculadas com diferentes concentrações de Meloidogyne incognita raça 1. Summary of analysis of variance of the characters gall incidence $(I G)$, number of galls in the root system (NGSR), number of eggs (NO) and reproduction factor (FR) in coriander cultivars, inoculated with different concentrations of Meloidogyne incognita race 1.

\begin{tabular}{lccccc}
\hline \multirow{2}{*}{ Fontes de variação } & \multirow{2}{*}{ GL } & \multicolumn{4}{c}{ Quadrados médios } \\
\cline { 3 - 6 } & & IG & NGSR & NO & FR \\
\hline Cultivares & 4 & $1,114^{* *}$ & $1,320^{* *}$ & $1,441^{* *}$ & $2,525^{* *}$ \\
Inóculos & 4 & $1,147^{* *}$ & $1,256^{* *}$ & $0,902^{* *}$ & $7,987^{* *}$ \\
Cultivares*Inóculos & 16 & $0,098^{\text {ns }}$ & $0,112^{*}$ & $0,147^{\text {ns }}$ & $0,419^{*}$ \\
Erro & 50 & 0,065 & 0,055 & 0,107 & 0,187 \\
\hline CV $(\%)$ e & & 16,92 & 15,32 & 20,38 & 43,24 \\
\hline Média & & 1,50 & 1,53 & 1,61 & 0,99
\end{tabular}

Nota: ** Significativo a 1\% de probabilidade pelo teste F. * Significativo a 5\% de probabilidade pelo teste F. ns Não significativo pelo teste F. ** Significant at $1 \%$ probability by the $\mathrm{F}$ test. Note: * Significant at 5\% probability by the F test. ns Not significant by the F test.

Fonte: Autoria própria. Own authorship.

Para a reação de genótipos de coentro ao $M$. incognita raça 1 quanto ao número de ovos e fator de reprodução, tem-se obtido valores de CV\% e acima de 20, como os encontrados por Diniz (2012) e Santos (2014) de 30,96 para número de ovos e 40,99 para o fator de reprodução, respectivamente. Isso demonstra que os resultados obtidos no presente estudo estão dentro dos observados para a cultura nos caracteres em questão.

Em trabalhos avaliando diferentes concentrações dos nematoides das galhas quanto a reação de genótipos de tomate cereja (BELAN et al., 2011), soja (TEIXEIRA, 2013) e 
algodoeiro (ABRÃO; MAZZAFERA, 2001) verificou-se reações distintas dos genótipos em função da concentração do inóculo, evidenciando que a depender do genótipo dentro da mesma espécie há diferentes comportamentos perante o patógeno, sendo necessária a identificação da concentração de inóculo a ser utilizada em experimentos que possibilite resultados mais confiáveis e obtenção de genótipos resistentes.

Para as variáveis PPE e CSR a interação cultivares*inóculos foi significativa a 5\% e 1\% de probabilidade, com coeficientes de variação de 6,64\% e 3,60\%, respectivamente. Já para PPS não houve interação significativa entre as fontes de variação, entretanto, ocorreu diferença nas fontes de variação cultivares e inóculos ao nível de $1 \%$ de probabilidade, apresentando coeficiente de variação de $29,71 \%$ (Tabela 2).

Tabela 2. Resumo da análise de variância dos caracteres porcentagem de plântulas emergentes (PPE), porcentagem de plantas sobreviventes (PPS) e comprimento do sistema radicular (CSR) em cultivares de coentro, inoculadas com diferentes concentrações de Meloidogyne incognita raça 1. Summary of analysis of variance of the characters percentage of emerging seedlings (PPE), percentage of surviving plants (PPS) and length of the root system (CSR) in coriander cultivars, inoculated with different concentrations of Meloidogyne incognita race 1 .

\begin{tabular}{lcccc}
\hline \multirow{2}{*}{ Fontes de variação } & \multirow{2}{*}{ GL } & \multicolumn{3}{c}{ Quadrados médios } \\
\cline { 3 - 5 } & & PPE & PP & CSR \\
\hline Cultivares & 4 & $277,78^{* *}$ & $9281,25^{* *}$ & $108,24^{* *}$ \\
Inóculos & 5 & $77,78^{\text {ns }}$ & $7466,67^{* *}$ & $173,83^{* *}$ \\
Cultivares*Inóculos & 20 & $77,78^{*}$ & $539,58^{\text {ns }}$ & $22,69^{* *}$ \\
Erro & 60 & 41,67 & 354,17 & 0,17 \\
\hline CV $(\%)$ & & 6,64 & 29,71 & 3,60 \\
\hline Média & & 97,22 & 63,33 & 11,60 \\
\hline
\end{tabular}

Nota: ${ }^{* *}$ Significativo a $1 \%$ de probabilidade pelo teste F. ${ }^{*}$ Significativo a $5 \%$ de probabilidade pelo teste F. ns: Não significativo pelo teste F. ** Significant at $1 \%$ probability by the F test. * Significant at $5 \%$ probability by the F test. ns Not significant by the F test.

Fonte: Autoria própria. Own authorship.

A porcentagem de plântulas emergentes não diferiu significativamente entre as cultivares para a maioria das concentrações do inóculo, exceto para as concentrações 1.000 ovos/planta e 4.000 ovos/planta, em que as cultivares Palmeira e Tapacurá apresentaram as menores médias, respectivamente (Tabela 3).

Não houve diferenças significativas entre as cultivares para a variável porcentagem de plantas sobreviventes nas concentrações 0 ovos/planta e 1.000 ovos/planta; enquanto nas demais concentrações, as cultivares Palmeira e Verdão não diferiram entre si, apresentando as menores médias em relação as demais cultivares. Com exceção da HTV Dom Luiz, as demais cultivares apresentaram comportamento diferenciado em função da concentração do inóculo. As cultivares Palmeira e Verdão apresentaram as menores médias nas concentrações 2.000 16.000 ovos/ planta. Já a cultivar Tapacurá expressou menores médias nas concentrações de 4.000 - 16.000 ovos/planta, enquanto a Tabocas obteve menores média em 8.000 e 16.000 ovos/planta. As maiores PPS em todas as cultivares foram obtidas nas concentrações até 2.000 ovos/planta. 
Tabela 3. Teste de agrupamento de Scott-Knott para as variáveis porcentagem de plântulas emergentes (PPE), porcentagem de plantas sobreviventes (PPS), comprimento do sistema radicular (CSR) em cultivares de coentro em casa de vegetação inoculadas com diferentes concentrações de $M$. incognita raça 1. Scott-Knott cluster test for the variables percentage of emerging seedlings (PPE), percentage of surviving plants (PPS), length of the root system $(C S R)$ in coriander cultivars in a greenhouse inoculated with different concentrations of $M$. incognita race 1 .

\begin{tabular}{ccccccc}
\hline \multirow{2}{*}{ Variáveis } & $\begin{array}{c}\text { Concentração } \\
\text { ovos/planta }\end{array}$ & Verdão & Tabocas & Tapacurá & Palmeira & $\begin{array}{c}\text { HTV Dom } \\
\text { Luiz }\end{array}$ \\
\cline { 2 - 7 } & 0 & $100 \mathrm{a}$ & $100 \mathrm{a}$ & $100 \mathrm{a}$ & $100 \mathrm{a}$ & $100 \mathrm{a}$ \\
& 1.000 & $100 \mathrm{~b}$ & $100 \mathrm{~b}$ & $100 \mathrm{~b}$ & $83,33 \mathrm{a}$ & $100 \mathrm{~b}$ \\
PPE (\%) & 2.000 & $100 \mathrm{a}$ & $100 \mathrm{a}$ & $100 \mathrm{a}$ & $91,67 \mathrm{a}$ & $100 \mathrm{a}$ \\
& 4.000 & $100 \mathrm{~b}$ & $100 \mathrm{~b}$ & $75,00 \mathrm{a}$ & $91,67 \mathrm{~b}$ & $100 \mathrm{~b}$ \\
& 8.000 & $100 \mathrm{a}$ & $100 \mathrm{a}$ & $91,67 \mathrm{a}$ & $91,67 \mathrm{a}$ & $100 \mathrm{a}$ \\
& 16.000 & $100 \mathrm{a}$ & $100 \mathrm{a}$ & $100 \mathrm{a}$ & $91,67 \mathrm{a}$ & $100 \mathrm{a}$ \\
\hline \multirow{3}{*}{ PPS (\%) } & 0 & $100 \mathrm{a}$ & $100 \mathrm{a}$ & $91,67 \mathrm{a}$ & $75 \mathrm{a}$ & $100 \mathrm{a}$ \\
& 1.000 & $58,33 \mathrm{a}$ & $100 \mathrm{a}$ & $83,33 \mathrm{a}$ & $75 \mathrm{a}$ & $100 \mathrm{a}$ \\
& 2.000 & $33,33 \mathrm{a}$ & $83,33 \mathrm{~b}$ & $100 \mathrm{~b}$ & $41,67 \mathrm{a}$ & $83,33 \mathrm{~b}$ \\
& 4.000 & $16,67 \mathrm{a}$ & $83,33 \mathrm{~b}$ & $66,67 \mathrm{~b}$ & $25 \mathrm{a}$ & $83,33 \mathrm{~b}$ \\
& 8.000 & $0 \mathrm{a}$ & $66,67 \mathrm{~b}$ & $41,67 \mathrm{~b}$ & $8,33 \mathrm{a}$ & $75 \mathrm{~b}$ \\
& 16.000 & $8,33 \mathrm{a}$ & $58,33 \mathrm{~b}$ & $58,33 \mathrm{~b}$ & $25 \mathrm{a}$ & $58,33 \mathrm{~b}$ \\
\hline & 0 & $14,73 \mathrm{a}$ & $16,70 \mathrm{c}$ & $15,60 \mathrm{~b}$ & $17,13 \mathrm{c}$ & $20,54 \mathrm{~d}$ \\
& 1.000 & $8,47 \mathrm{a}$ & $15,13 \mathrm{c}$ & $13,30 \mathrm{~b}$ & $12,13 \mathrm{~b}$ & $18,97 \mathrm{~d}$ \\
& 2.000 & $4,83 \mathrm{a}$ & $11,48 \mathrm{~b}$ & $12,80 \mathrm{c}$ & $14,43 \mathrm{~d}$ & $13,00 \mathrm{c}$ \\
& 4.000 & $10,77 \mathrm{~b}$ & $13,30 \mathrm{~d}$ & $7,90 \mathrm{a}$ & $11,80 \mathrm{c}$ & $13,77 \mathrm{~d}$ \\
& 8.000 & $0,00 \mathrm{a}$ & $4,87 \mathrm{~b}$ & $11,77 \mathrm{e}$ & $11,03 \mathrm{~d}$ & $8,73 \mathrm{c}$ \\
& 16.000 & $8,87 \mathrm{~b}$ & $3,77 \mathrm{a}$ & $9,20 \mathrm{~b}$ & $10,73 \mathrm{c}$ & $12,10 \mathrm{~d}$ \\
\hline
\end{tabular}

Nota: ${ }^{* *}$ Significativo a $1 \%$ de probabilidade pelo teste F. ${ }^{*}$ Significativo a $5 \%$ de probabilidade pelo teste F. ns: Não significativo pelo teste $\mathrm{F}$. ** Significant at $1 \%$ probability by the $\mathrm{F}$ test. $*$ Significant at $5 \%$ probability by the F test. ns Not significant by the F test.

Fonte: Autoria própria. Own authorship.

A presença do patógeno promoveu variação no comprimento do sistema radicular entre as cultivares, em que a cultivar HTV Dom Luiz diferiu significativamente das demais, apresentando maior comprimento na maioria das concentrações do inóculo, exceto nas concentrações de 2.000 e 8.000 ovos/planta, nas quais as cultivares Palmeira e Tapacurá apresentaram maiores desenvolvimentos radiculares, respectivamente. Para todas as cultivares a ausência do patógeno (0 ovo/planta) resultou em maior desenvolvimento do sistema radicular, sendo as concentrações até 4.000 ovos/planta as que promoveram maior crescimento do sistema radicular, possibilitando uma avaliação mais precisa quanto a reação dos genótipos a infecção causada pelo nematoide (Figura 1). 


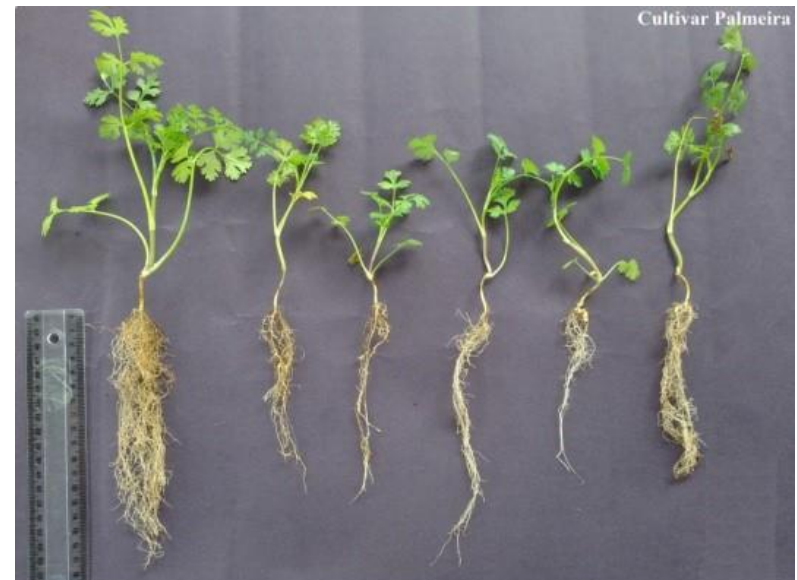

A
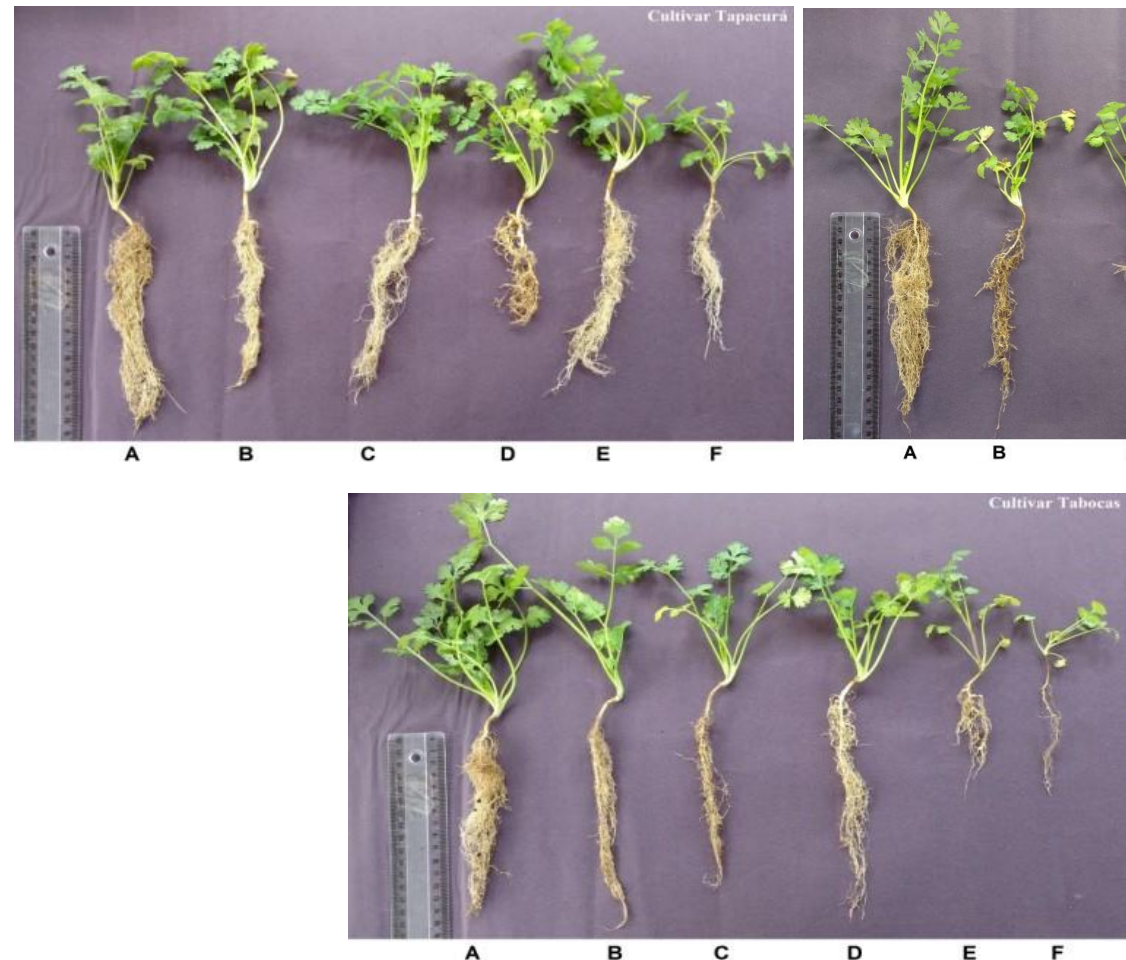
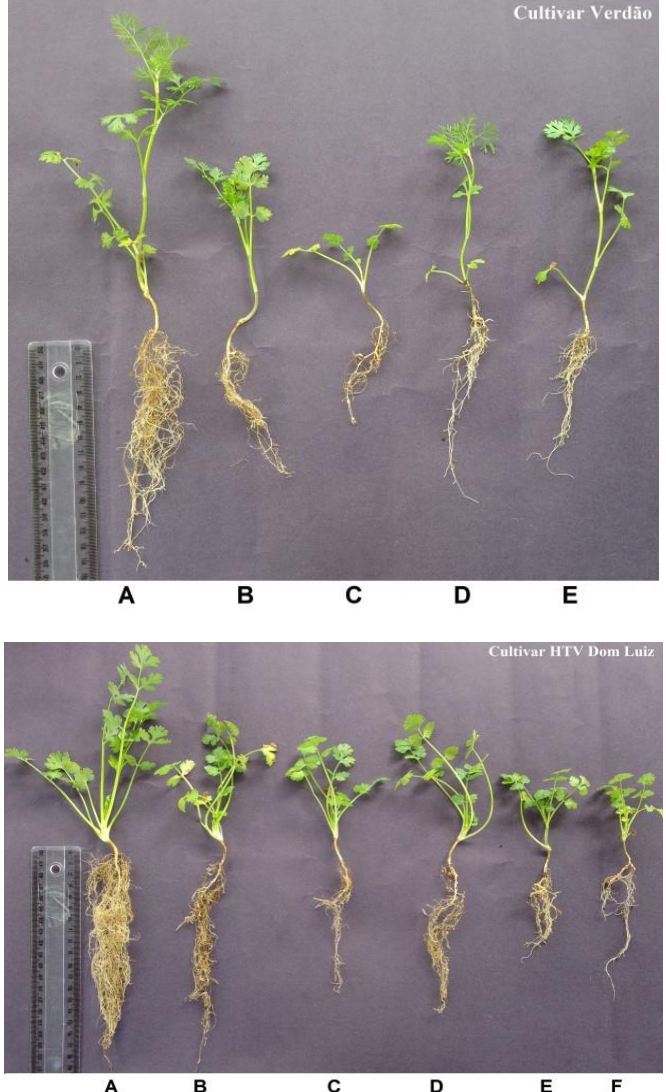
desorganização fisiológica causada pelo parasitismo do Meloidogyne spp. (CAMPOS, 2000), que segundo Belan et al. (2011), o subdesenvolvimento do sistema radicular implicou em redução de características de crescimento como matéria seca das folhas, matéria seca do caule e matéria seca total da maioria dos acessos de tomate cereja avaliados. Fato semelhante foi observado no presente estudo, onde o aumento do nível do inóculo promoveu uma redução do sistema radicular e paralelamente da parte aérea das cultivares analisadas (Figura 1), pois o crescimento de uma planta é inversamente proporcional a densidade populacional inicial de espécies do gênero Meloidogyne spp. (KINLOCH, 1982).

$\mathrm{Na}$ incidência de galhas houve diferença significativa entre as cultivares para as concentrações utilizadas, exceto em 16.000 ovos/planta. Na concentração 1.000 ovos/planta a cultivar Palmeira apresentou a menor média, diferindo significativamente das demais. Em 2.000 e 4.000 ovos/planta as cultivares Palmeira e Verdão apresentaram médias inferiores aos demais genótipos em estudo. Em 8.000 ovos/planta, as cultivares Verdão, Tapacurá e Palmeira apresentaram as menores médias. A concentração de inóculo até 2.000 ovos/planta resultou nas maiores médias de notas para IG na maioria das cultivares (Tabela 4).

Para o número de galhas no sistema radicular, houve diferença significativa entre as cultivares para as concentrações utilizadas, onde as cultivares Verdão e Palmeira apresentaram as menores médias, exceto em 16.000 ovos/planta já que não houve diferença entre as cultivares.

Na variável número de ovos não houve diferença significativa entre as cultivares nas concentrações de 8.000 e 16.000 ovos/planta, possivelmente devido ao subdesenvolvimento dos sistemas radiculares nestas concentrações. Na concentração de 1.000 ovos/planta as cultivares Verdão, Tapacurá e Palmeira apresentaram as menores médias. Em 2.000 ovos/planta as cultivares Verdão e Palmeira expressaram as menores médias, enquanto que em 4.000 ovos/planta apenas a Palmeira apresentou média inferior as demais cultivares.

Considerando a variação existente entre as cultivares, no fator de reprodução houve comportamento semelhante ao observado para o número de ovos. Já a nível de cultivar, a Verdão, Tabocas e Tapacurá obtiveram menores médias para as concentrações de 8.000 e 16.000 ovos/planta. A HTV Dom Luiz obteve as menores médias nas concentrações de 4.000 - 16.000 ovos/planta, enquanto que para a Palmeira não houve diferença entre as concentrações avaliadas.

Nas concentrações de 8.000 e 16.000 ovos/planta foi verificada em todas as cultivares necrose na base do caule da planta e necrose do sistema radicular, levando as plantas a morte. Em algumas culturas, o ataque dos nematoides de galhas pode tornar as plantas mais suscetíveis à ocorrência de outros agentes causais de doenças, como os fungos, que em algumas cultivares de algodoeiro parasitado por $M$. incógnita promovem doença vascular de natureza fúngica, a Fusariose ou Murcha Fusariana, acarretando na morte da planta (FERRAZ; BROWN, 2016). 
Tabela 4. Teste de agrupamento de Scott-Knott para as variáveis incidência de galhas (IG), número de galhas no sistema radicular (NGSR), número de ovos (NO) e fator de reprodução (FR) em cultivares de coentro em casa de vegetação inoculadas com diferentes concentrações de $M$. incognita raça 1. Scott-Knott cluster test for the variables gall incidence (IG), number of galls in the root system (NGSR), number of eggs (NO) and reproduction factor (FR) in coriander cultivars in a greenhouse inoculated with different concentrations of $M$. incognita race 1 .

\begin{tabular}{|c|c|c|c|c|c|c|}
\hline \multirow[b]{2}{*}{ Variáveis } & \multirow[b]{2}{*}{$\begin{array}{c}\text { Concentração } \\
\text { ovos/planta }\end{array}$} & \multicolumn{5}{|c|}{ Cultivares } \\
\hline & & Verdão & Tabocas & Tapacurá & Palmeira & $\begin{array}{l}\text { HTV Dom } \\
\text { Luiz }\end{array}$ \\
\hline \multirow{5}{*}{ IG } & 1.000 & $2,99 \mathrm{~b}$ & $3,65 \mathrm{~b}$ & $3,31 \mathrm{~b}$ & $1,61 \mathrm{a}$ & $3,65 \mathrm{~b}$ \\
\hline & 2.000 & $2,22 \mathrm{a}$ & $4,00 \mathrm{~b}$ & $4,00 \mathrm{~b}$ & $1,90 \mathrm{a}$ & $3,31 \mathrm{~b}$ \\
\hline & 4.000 & $2,29 \mathrm{a}$ & $3,96 \mathrm{~b}$ & $4,00 \mathrm{~b}$ & $1,30 \mathrm{a}$ & $3,65 \mathrm{~b}$ \\
\hline & 8.000 & $1,00 \mathrm{a}$ & $2,50 \mathrm{~b}$ & $1,00 \mathrm{a}$ & $1,00 \mathrm{a}$ & $2,50 \mathrm{~b}$ \\
\hline & 16.000 & $1,00 \mathrm{a}$ & $2,22 \mathrm{a}$ & $1,54 \mathrm{a}$ & $1,00 \mathrm{a}$ & $1,30 \mathrm{a}$ \\
\hline \multirow{5}{*}{ NGSR } & 1.000 & $2,31 \mathrm{a}$ & $4,32 \mathrm{~b}$ & $4,00 \mathrm{~b}$ & $1,90 \mathrm{a}$ & $3,96 \mathrm{~b}$ \\
\hline & 2.000 & $2,62 \mathrm{a}$ & $3,65 \mathrm{~b}$ & $4,32 \mathrm{~b}$ & $2,22 \mathrm{a}$ & $3,65 \mathrm{~b}$ \\
\hline & 4.000 & $1,00 \mathrm{a}$ & $4,67 \mathrm{~b}$ & $3,24 \mathrm{~b}$ & $1,00 \mathrm{a}$ & $4,32 \mathrm{~b}$ \\
\hline & 8.000 & $1,00 \mathrm{a}$ & $2,79 \mathrm{~b}$ & $1,61 \mathrm{~b}$ & $1,00 \mathrm{a}$ & $1,90 \mathrm{~b}$ \\
\hline & 16.000 & $1,00 \mathrm{a}$ & $1,99 \mathrm{a}$ & $1,61 \mathrm{a}$ & $1,30 \mathrm{a}$ & $1,30 \mathrm{a}$ \\
\hline \multirow{5}{*}{ NO } & 1.000 & $2,31 \mathrm{a}$ & $5,02 \mathrm{~b}$ & $2,99 \mathrm{a}$ & $1,30 \mathrm{a}$ & $4,67 \mathrm{~b}$ \\
\hline & 2.000 & $2,35 \mathrm{a}$ & $5,05 \mathrm{~b}$ & $3,96 \mathrm{~b}$ & $1,61 \mathrm{a}$ & $5,02 \mathrm{~b}$ \\
\hline & 4.000 & $3,35 \mathrm{~b}$ & $4,67 \mathrm{~b}$ & $3,06 \mathrm{~b}$ & $1,00 \mathrm{a}$ & $3,96 \mathrm{~b}$ \\
\hline & 8.000 & $1,00 \mathrm{a}$ & $2,40 \mathrm{a}$ & $1,61 \mathrm{a}$ & $1,53 \mathrm{a}$ & $2,49 \mathrm{a}$ \\
\hline & 16.000 & $1,30 \mathrm{a}$ & $2,31 \mathrm{a}$ & $1,90 \mathrm{a}$ & $1,90 \mathrm{a}$ & $1,90 \mathrm{a}$ \\
\hline \multirow{5}{*}{ FR } & 1.000 & $2,19 \mathrm{a}$ & $6,67 \mathrm{~b}$ & $3,03 \mathrm{a}$ & $1,08 \mathrm{a}$ & $8,52 \mathrm{~b}$ \\
\hline & 2.000 & $0,92 \mathrm{a}$ & $3,57 \mathrm{~b}$ & $2,22 \mathrm{~b}$ & $0,41 \mathrm{a}$ & $5,86 \mathrm{c}$ \\
\hline & 4.000 & $1,30 \mathrm{~b}$ & $2,28 \mathrm{~b}$ & $1,02 \mathrm{~b}$ & $0,03 \mathrm{a}$ & $1,02 \mathrm{~b}$ \\
\hline & 8.000 & $0,00 \mathrm{a}$ & $0,21 \mathrm{a}$ & $0,11 \mathrm{a}$ & $0,05 \mathrm{a}$ & $0,25 \mathrm{a}$ \\
\hline & 16.000 & $0,02 \mathrm{a}$ & $0,13 \mathrm{a}$ & $0,13 \mathrm{a}$ & $0,06 \mathrm{a}$ & $0,12 \mathrm{a}$ \\
\hline
\end{tabular}

Nota: ${ }^{* *}$ Significativo a $1 \%$ de probabilidade pelo teste F. ${ }^{*}$ Significativo a $5 \%$ de probabilidade pelo teste F. ns: Não significativo pelo teste F. Note: ** Significant at $1 \%$ probability by the F test. * Significant at 5\% probability by the F test. ns Not significant by the F test.

Fonte: Autoria própria. Own authorship.

Observando os gráficos de regressão (Figura 2), todas as cultivares apresentaram os maiores fatores de reprodução (acima de 1) na concentração de 1.000 ovos/planta, havendo a redução do FR e NGSR à medida que se aumentou a concentração do inóculo. Teixeira (2013) observou comportamento semelhante nas cultivares de soja BRSGO Santa Cruz e BRSGO Paraíso inoculadas com $M$. incognita, as quais apresentaram uma redução na penetração de J2 e presença de J3 em concentrações de inóculo acima de 3640 e 2821 ovos/planta, respectivamente. 

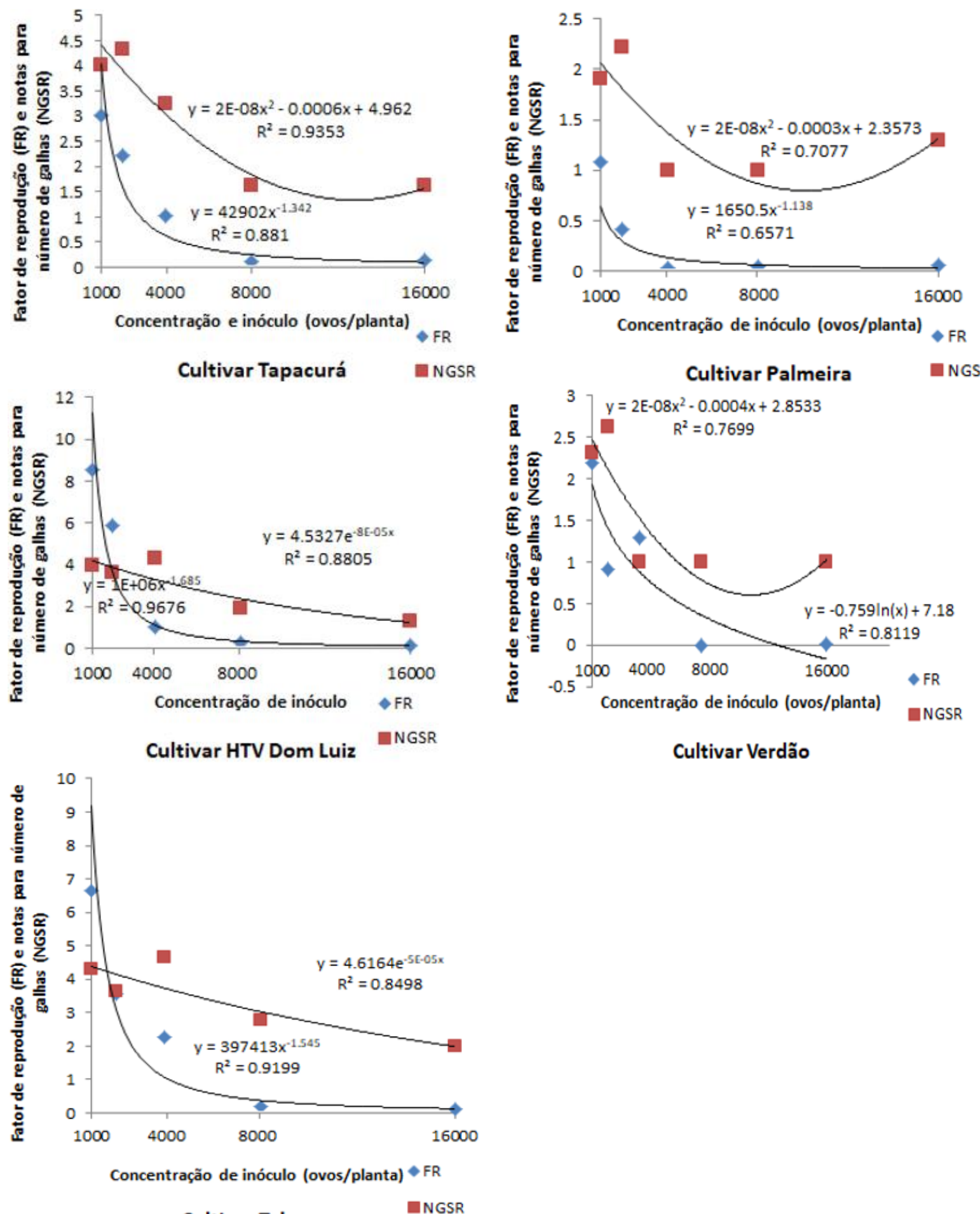

Cultivar Verdão

Figura 2. Fator de reprodução (FR) e número de galhas no sistema radicular (NGSR) de plantas de cinco cultivares de coentro, aos 30 dias após inoculação, em função de diferentes concentrações de inóculo. Reproduction factor (FR) and number of galls in the root system (NGSR) of plants of five coriander cultivars, at 30 days after inoculation, depending on different inoculum concentrations.

Fonte: Autoria própria. Own authorship.

O aumento das concentrações de inóculo possivelmente promove a competição entre os nematoides por sítios de alimentação, limitando tanto a penetração quanto o desenvolvimento 
do patógeno (TEIXEIRA, 2013), havendo um crescimento exponencial inicialmente, em baixos níveis populacionais, porém, a competição por alimento resulta em menores taxas de crescimento ao passar do tempo (FERRAZ, 2001).

Com aumento da concentração, o fator de reprodução poderá classificar os genótipos como sendo resistentes sem serem, apresentando um falso positivo. Na concentração de 1.000 ovos/planta todas as cultivares apresentaram FR>1 sendo consideradas suscetíveis pela classificação de Oostenbrik (1966), enquanto que na concentração de 2.000 ovos/planta as cultivares Verdão e Palmeira apresentaram FR<1. Em 8.000 e 16.000 ovos/planta todas as cultivares apresentaram $\mathrm{FR}<1$, e seriam classificadas como resistentes, sendo na realidade suscetíveis (Tabela 4). Resultados semelhantes foram observados em mudas de cafeeiro cultivadas em vasos de $700 \mathrm{~mL}$ e inoculadas com diferentes concentrações de $M$. incognita (1, 2, 4, 8 e 16 ovos $/ \mathrm{cm}^{3}$ ), em que os maiores FR foram obtidos nas menores densidades populacionais do patógeno (MACHADO et al., 2015).

Segundo Greco e Di Vito (2009), em populações iniciais muito elevadas do nematoide, ocorre um dano severo as raízes da planta hospedeira devido a competição entre os indivíduos por sítios de alimentação no hospedeiro, resultando em $\mathrm{FR}<1$, o que caracterizaria uma reação de resistência, mesmo em plantas suscetíveis ao nematoide. Isto justifica os resultados encontrados para os FR encontrados no presente estudo.

Além disso, em altas densidades populacionais do nematoide, a resposta de cultivares tidas como resistentes pode ser de suscetibilidade, por apresentarem intolerância ao patógeno ou reação de resistência do tipo hipersensibilidade, com morte celular atrelada ao mecanismo de resistência, como já observado para a relação café x M. exigua (ANTHONY et al., 2005), gerando resultados pouco confiáveis ao melhoramento da cultura (GRECO; DI VITO, 2009). Desta forma, é fundamental a busca pela concentração de inóculo que promova uma classificação dos indivíduos de forma a representar ao máximo o potencial genético quanto à reação de resistência aos nematoides das galhas, dentro de cada espécie, tendo em vista a diferenciação da relação hospedeiro X patógeno entre e dentro das espécies vegetais.

A utilização da concentração de 1.000 ovos/plantas de $M$. incognita raça 1 na semeadura é mais adequada para a avaliação de genótipos de coentro quanto a reação ao patógeno, devido a obtenção de maiores valores do FR, caracterizando de forma mais representativa as cultivares avaliadas no presente trabalho, com base nas variáveis PPE, PPS, CSR, IG, NGSR, NO e FR. A inoculação na semeadura e avaliação aos 30 dias permitiu a diferenciação entre os genótipos com uma redução de aproximadamente $50 \%$ do tempo que normalmente é necessário nas metodologias que são utilizadas para realização desta etapa fundamental dos programas de melhoramento genético da cultura em relação à resistência ao nematoide para as variáveis IG, NGSR, NO e FR.

\section{CONCLUSÃO}

A concentração de inóculo com 1.000 ovos/planta é a mais indicada, por possibilitar um bom desenvolvimento do sistema radicular e classificar corretamente os genótipos por meio do fator de reprodução do patógeno. Além disso, a inoculação na semeadura e avaliação aos 
30 dias foram suficientes para diferenciar as cultivares avaliadas e verificar a infecção causada pelo nematoide.

\section{REFERÊNCIAS BIBLIOGRÁFICAS}

ABRÃO, M. M.; MAZZAFERA, P. Efeitos do nível de inóculo de Meloidogyne incognita em algodoeiro. Bragantia, Campinas, v. 60, n. 1, p.19-26, 2001. http://www.scielo.br/scielo.php?script=sci_arttext\&pid=S0006-87052001000100003. Acesso em: 07 mar. 2020.

ANTHONY, F.; TOPART, P.; MARTINEZ, A.; SILVA, M.; NICOLE, M. Hypersensitivelike reaction conferred by the Mex-1 resistance gene against Meloidogyne exigua in coffee. Plant Pathology, Oxford, v. 54, n 4, p. 476-482, 2005. Disponível em: https://bsppjournals.onlinelibrary.wiley.com/doi/abs/10.1111/j.13653059.2005.01239.x.

Acesso em: 07 mar. 2020.

BELAN, L. L.; ALVES, F. R; COSTA, D. C.; FONSECA, S. O.; MORAES, W. B.; SOUZA, A. F.; JESUS JUNIOR, W. C. Efeitos de densidades crescentes de inóculo de Meloidogyne javanica no desenvolvimento vegetativo de genótipos de tomateiro cereja. Revista Tropica: Ciências Agrarias e Biologicas, Chapadinha, v. 5, n. 1, p.22-30, 2011. Disponível em: http://www.periodicoseletronicos.ufma.br/index.php/ccaatropica/article/view/271/309. Acesso em: 07 mar. 2020.

BONETI, J. I. S.; FERRAZ, S. Modificação do método de Hussey and Barker para extração de ovos de Meloidogyne exigua de raízes de cafeeiro. Fitopatologia Brasileira, Brasília, v. 6, n. $3, \quad$ p.553-553, 1981. Disponível em: http://www.scielo.br/scielo.php?script=sci_nlinks\&ref=000030\&pid=S180786212010000200 00600002\&lng=en. Acesso em: 07 mar. 2020.

CAMPOS, V. P. Doenças causadas por nematóides em tomate. In: ZAMBOLIM, L.; VALE F. X. R.; COSTA, H (Ed). Controle de doenças de plantas - Hortaliças. v. 2. Viçosa, MG: UFV. 2000. Cap. 23, p.801-842.

DIAS-ARIEIRA, C. R.; SANTANA, S. M.; SILVA, M. L.; FURLANETTO, C.; RIBEIRO, R. C. F.; LOPES, E. A. Reação de cultivares de Mamona (Ricinus communis L.) e Girassol (Helianthu sannuus L.) a Meloidogyne javanica, M. incognita e M. Paranaensis. Nematologia Brasileira, Piracicaba, v. 33, n. 1, p.61-66, 2009. Disponível em: https://nematologia.com.br/files/revnb/33_1.pdf. Acesso em: 07 mar. 2020.

DINIZ, G. M. M. Resistência do coentro (Coriandrum sativum L.) à Meloidogyne incognita (Raça 1 e 3) e Meloidogyne javanica. 2012. 56 f. Dissertação (Mestrado em Melhoramento genético de plantas) - Universidade Federal Rural de Pernambuco, Recife, 2012.

EL-MOOR, R. D.; PEIXOTO, J. R.; RAMOS, M. L. G.; MATTOS, J. K. A. Reação de genótipos de maracujazeiro-azedo aos nematoides de galhas (Meloidogyne incognita e Meloidogyne javanica). Bioscience Journal, Uberlândia, v. 25, n. 1, p.53-59, 2009. 
Disponível em: http://www.seer.ufu.br/index.php/biosciencejournal/article/view/6775/4472. Acesso em: 07 mar. 2020.

FERRAZ, L. C. C. B. As meloidoginoses da soja: passado, presente e futuro. In: SILVA, J. F. V. (org.) Relações parasito-hospedeiro nas meloidoginoses da soja. Londrina: Embrapa Soja/Sociedade Brasileira de Nematologia, 2001. Cap. 1, p. 15-38.

FERRAZ, L. C. C. B.; BROWN, D. J. F. Nematologia de plantas: fundamentos e importância. Manaus: Norma Editora. 2016. 251p.

FERREIRA, D. F. Sisvar: a computer statistical analysis system. Ciência e Agrotecnologia, Lavras, v. 35, n. 6, p.1039-1042, 2011. Disponível em: http://www.scielo.br/scielo.php?pid=S1413-70542011000600001\&script=sci_arttext. Acesso em: 07 mar. 2020.

FERREIRA, S. GOMES, L. A. A.; GASPARINO, F. C.; CARVALHO FILHO, J. L. S.; MALUF, W. R. Caracterização de famílias F 2:3 de alface para resistência ao nematoidedas galhas. Revista Agrogeoambiental, Pouso Alegre, v. 5, n. 2, p.35-42, 2013. Disponível em: https://agrogeoambiental.ifsuldeminas.edu.br/index.php/Agrogeoambiental/article/view/439/4 82. Acesso em: 07 mar. 2020.

GRECO, N.; DI VITO, M. Population dynamics and damage levels. In: PERRY, R. N.; MOENS, M.; STARR, J. L. (ed.). Root-knot nematodes. Cambridge: CAB International, 2009. Cap. 11, p. 246-274.

HUSSEY, R. S.; BARKER, K. R. A comparison of methods collecting inocula of Meloidogyne spp. including a new technique. Plant Disease Reporter, Washington, v. 57, n. 12, p.1025-1028, $1973 . \quad$ Disponível em: http://www.scielo.br/scielo.php?script=sci_nlinks\&ref=000082\&pid=S010029452011000300 01100013\&lng=pt. Acesso em: 07 mar. 2020.

INSTITUTO NACIONAL DE METEOROLOGIA - INMET. Estações Convencionais. Brasília, DF, 2018. Disponível em: http://www.inmet.gov.br/portal/index.php?r=estacoes/estacoesConvencionais. Acesso em: 05 jun. 2020.

KINLOCH, R. A. The relationship between soil populations of Meloidogyne incognita and yield reduction of soybean in the coastal plain. Journal of Nematology, College Park, v. 14, n. $2, \quad$ p.162-167, 1982. Disponível em: https://www.ncbi.nlm.nih.gov/pmc/articles/PMC2618163/. Acesso em: 07 mar. 2020.

MACHADO, A. C. Z.; BICALHO, A. C.; SILVA, S. A. Ajuste de datas de avaliação e densidades populacionais de Meloidogyne incognita visando a avaliação da resistência de cafeeiros. In: SIMPÓSIO DE PESQUISA DOS CAFÉS DO BRASIL, 9., 2015, Curitiba. Anais [... Curitiba: [s.n.], 2015. p. 1-3. Disponível em: http://www.sbicafe.ufv.br/bitstream/handle/123456789/4128/106_IX-SPCB-

2015.pdf? sequence=1\&isAllowed=y. Acesso em: 15 jun. 2019.

MAKISHIMA, N.; MELO, L. A. S.; COUTINHO, V. F.; ROSA, L. L. Projeto horta solidária: cultivo de hortaliças. Jaguariúna: Embrapa Meio Ambiente, 2010. 24p. 
MCCARTER, J. P. The genome sequence of the plant-parasitic roundworm Meloidogyne incognita opens new avenues to boosting food production. Nature Biotechnology, New York, v. 26, n. 8, p.882-884, 2008.

OOSTENBRINK, M. Major characteristics of the relation between nematodes and plants. Mendelingen Landbouwhogeschool, Wageningen, v. 66, n. 4, p.1- 46, 1996.

PINHEIRO, J. B.; PEREIRA, R. B. Manejo de nematoides na cultura do coentro e salsinha. Brasília, DF: Embrapa Hortaliças, 2016. 8 p. (Circular Técnica, 149).

PINHEIRO, J. B.; AMARO, G. B.; PEREIRA, R. B. Ocorrência e controle de nematoides em hortaliças folhosas. Brasília, DF: Embrapa Hortaliças, 2010a. 10 p. (Circular Técnica, 89).

PINHEIRO, J. B.; CARVALHO, A. D. F.; VIEIRA, J. V. Reação de cultivares de cenoura a Meloidogyne incognita raça 1 e Meloidogyne mayaguensis. Brasília, DF: Embrapa Hortaliças - Embrapa Hortaliças, 2010b. 20 p. (Boletim de Pesquisa e Desenvolvimento, 69).

SANTOS, A. M. M. Comportamento de população melhorada de coentro quanto à reação de resistência à Meloidogyne incognita raça 1. 2014. 33 f. Dissertação (Mestrado em Melhoramento Genético de Plantas) - Universidade Federal Rural de Pernambuco, Recife, 2014.

SANTOS, A. V. Reação de Cafeeiros (Coffea canephora) ao Nematoide-das- Galhas Meloidogyne incognita sob condições controladas de inoculação. 2017. 118 f. Tese (Doutorado em Biodiversidade e Biotecnologia da Rede Bionorte) - Universidade Federal do Amazonas, Manaus, 2017.

SANTOS, C. D. G.; CARVALHO, S. L. F.; SILVA, M. C. L. Solarização do solo em sacos plásticos para o controle dos nematoides das galhas, Meloidogyne incognita e M. javanica. Revista Ciência Agronômica, Fortaleza, v. 37, n. 3, p.350-356, 2006. Disponível em: http://ccarevista.ufc.br/seer/index.php/ccarevista/article/view/179/173. Acesso em: 07 mar. 2020 .

TEIXEIRA, R. A. Reação de cultivares de soja a Meloidogyne incognita e M. javanica. 2013. 60 f. Tese (Doutorado em Genética e Melhoramento de Plantas) - Universidade Federal de Goiás, Escola de Agronomia, Goiânia, 2013. 